\title{
Economic oscillating systems
}

\author{
Alexander A. Antonov ${ }^{1 *}$ \\ ${ }^{1}$ Research Center of Information Technologies "TELAN Electronics" of the IAOI \\ * Correspondence author: tel/fax (380) 444243587,e-mai:telan@bk.ru \\ ABSTRACT
}

\begin{abstract}
The inevitability of economic crises is objectively determined by ignorance of the mechanics of the "black box" of the economy and the inappropriate market policy. The article shows that the fundamental market process "goods-money-goods" is described with a second-degree differential equation, and, therefore, is potentially an oscillation process. However, in order to implement the economic oscillation processes of the commodity-money circulations, certain conditions have to be fulfilled, which are usually not fulfilled on their own. In order to comply with these conditions, the participants of the commodities market should be organized in a certain way. Cognition and use of the described oscillation processes in the economy allows making its development controlled, predictable and, eventually, crisis-proof. The article presents the main principles of the new science - the theory of oscillation economic systems, which allows developing new highly efficient economic structures. This new science even allows describing and ensures implementation of new economic processes, for instance, resonant processes.
\end{abstract}

Key words: "Goods-money-goods", Economic "black box", Supply and demand curves, Economic oscillation process, Differential equations.

JEL Classification $\mathrm{C} 02 \cdot \mathrm{G} 01 \cdot \mathrm{M} 21 \cdot \mathrm{O} 16$

\section{INTRODUCTION}

In 1831, one of the members of the British Parliament asked Michael Faraday, the founder of the theory of electricity, how people can benefit from the discoveries he made. Faraday replied that he didn't know. And in 60 years the world saw the beginning of the industrial revolution based on the use of electricity (Chebotarev 2004).

The market-oriented information technologies presented below can be useful at the present moment, as they are able to provide for the crisis-free development of the economy.

Oscillation processes in the economy: Despite the efforts of politicians, economists and businessmen, an economic upturn always ends up in a recession. In other words, the process of economic development always contains an oscillation component (Zarnowitz 1996; Mokyr 2003; Bannock and Baxter 2009; Barber 2009).

This oscillation component was found back in the $19^{\text {th }}$ century. Nevertheless, the founders of the classical school of economics A. Smith, D. Ricardo, J. B. Say denied the possibility of global economic crises.

As opposed to them, T. R. Maltus, J.-C. L. S. de Sismondi, K. H. Marx, J. A. Schumpeter, A. Kleinknecht, N. D. Kondratieff, C. Freeman, S. S. Kuznets, J. B. Clark, W.W. Rostow and many others acknowledged the existence of crises in the economy, but explained the phenomenon in different ways.

However, during the Great Depression of 1929-1933, the then dominant neoclassical school proved its failure to develop the global anti-recessionary instruments. And then J. M. Keynes suggested the theory of regulated capitalism. The Keynesian theory of cycle formed the basis of the government antirecessionary policy. However, the subsequent economic crises undermined the confidence in the Keynesian theory.

This is why the Keynesian theory was replaced by M. Friedman's monetary theory of cycle, according to which the cycles of economic development and the corresponding crises, inflation, unemployment are caused by the incorrect monetary policy of the government, seen in the imbalance of the circulating money supply and the Gross Domestic Product (GDP) growth rate. However, the monetary theory of cycle also failed to prevent the current global economic crisis.

The given overview is far from complete. But it still allows to see that historical conditions, the level of the scientific and technical development, economic theories and means of fighting economic oscillations have been changing, but crises remained. Moreover, the process in the economic "black box" has also 
remained unknown. Consequently, all of the above mentioned hypothetic reasons causing crises have remained unproven. Even the necessity of battling the crises as a consequence of oscillation economic processes has not been proven.

For instance, in agriculture business, despite the reliable data on the reasons behind seasonal weather changes, no one suggests the ways to fight winter.

So far, each time we deal with a crisis, people believe that it is the consequence of an evil concurrence of fatal circumstances and the wrong strategy of fighting these circumstances.

However, this approach is incorrect. Misperception of the essence of the global market as an oscillation system is the fundamental factor contributing to the failure of the battle with crises. Fighting the oscillations of an oscillation system is obviously unnatural.

This is why a different objective has to be set instead of fighting economic oscillation processes we should study them and learn to use them.

Differential equation for the "goods-moneygoods" oscillation process: Engineers know that all types of oscillations, such as mechanical, acoustic, electro-technical, etc., are described by differential equations not lower than of the second degree. Consequently, the same equations should describe economic oscillation processes, if the latter actually exist.

To make sure they do exist, let us consider the fundamental market process described by the formula "goods-money-goods" and prove that it is an oscillation process.

The functional scheme of the simplest link of the commodities market is given in Fig. 1 .

As can be seen, it includes a generic aggregate vendor-manufacturer (hereinafter referred to as the vendor) of a commodity, and a generic aggregate buyer (hereinafter referred to as the buyer) of this commodity.

A commercial transaction between them is in fact described not by an algebraic equation (e.g., given graphically by means of the supply and demand curves), but by a differential equation (Antonov 2010), as it is the only equation taking into account the background of the transaction. Indeed, people never sell or buy without studying the market situation.

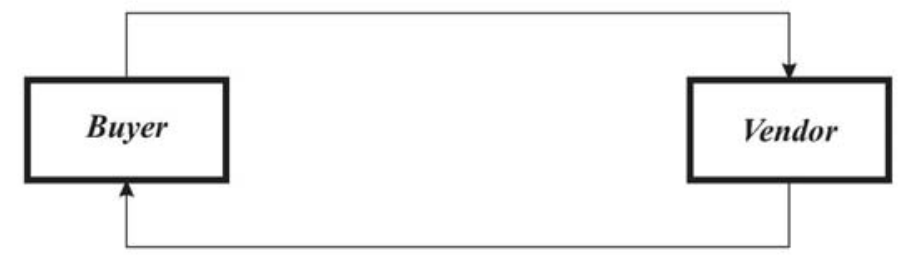

Fig. 1 Functional scheme of the simplest link of the commodities market

Thus, the behavior of the buyer in the market is described by the formula

$M_{B}(t)=\frac{1}{T_{B}} \int_{0}^{t} Q_{B}(t) P_{B}(t) d t$

or the inverse formula

$Q_{B}(t) P_{B}(t)=T_{B} \frac{d M_{B}(t)}{d t}$

where $M_{B}(t)$ is the current expenses of the buyer (the amount of the circulating assets);

$P_{B}(t)$ is the current retail market price of goods purchased by the buyer;

$Q_{B}(t)$ is the current amount of goods purchased by the buyer;
$P_{B}(t) Q_{B}(t)$ is the flow of circulating assets (medium of exchange) of the buyer;

$T_{B}$ is the useful life of goods purchased by the buyer.

Consequently, the expenses of the buyer, according to formula 1a, equal to accrued expenses for the purchase of the necessary amount of goods taking into account the purchase dynamics.

The behavior of the vendor in the market is described by the formula

$P_{V}(t)=\frac{1}{Q_{V}(t) T_{V}} \int_{0}^{t} M_{V}(t) d t$

or the inverse formula 
$M_{V}(t)=T_{V} \frac{d\left[Q_{V}(t) P_{V}(t)\right]}{d t}$

where $P_{V}(t)$ is the current wholesale market price of goods;

$Q_{V}(t)$ is the current amount of goods produced by the vendor;

$P_{V}(t) Q_{V}(t)$ is the flow of the vendor's circulating assets;

$M_{V}(t)$ is the current income of the vendor (amount of circulating assets), covering production costs and generating profit;

$T_{V}$ is the duration of production of goods by the vendor.

Consequently, the sale price of goods in accordance with formula (2a) equals to the accrued expenses of the vendor and received profit divided by the quantity of goods produced.

As is seen, both the vendor and the buyer use their averaged estimates when making a transaction in accordance with formulae (2) and (3).

In this particular simplest case, when there is only one vendor and only one buyer, $Q_{V}(t)=Q_{B}(t)=Q(t)$, $P_{V}(t)=P_{B}(t)=P(t)$. Then, using the economic equivalent of the second Kirchhoff's law borrowed from the electric circuits theory (Bode 1945; Balabanian 1994; Franco 1994; Cogdell 1999; Steinmetz 2006; Bell 2009), we can argue that the sum of circulating assets in the disposal of the subjects of economic activity (e.g., the buyer and the vendor) in a closed functional link shown in Fig. 1, equals zero at any moment of time (and this is the formulation of the second Kirchhoff's law as applied to economics), i.e.

$T_{V} \frac{d Q(t) P(t)}{d t}+\frac{1}{T_{B}} \int_{0}^{t} Q(t) P(t) d t=0$

And using formulas (1), we obtain the second-degree differential equation from (3a)

$T_{V} T_{B} \frac{d^{2} M_{B}(t)}{d t^{2}}+M_{B}(t)=0$

which makes it possible to conclude that the functional scheme of the simplest link of the commodities market given in Fig. 1 actually corresponds to the oscillating system. This can be easily verified by analyzing with reference to formulae (1) and (2) the plotted solution of this differential equation (see Fig. 2).
However, it is possible to change the shape of these oscillations, for instance, by using different nonlinear systems (Andronov et al. 1966) or systems with commutable parameters (Emelyanov 1995; Sabanovic et al. 2004). But should we actually do this? Should we really fight the economic oscillation processes?

Probably, it makes more sense to use the oscillating economic systems in the oscillation mode. However, we need to take into account that the formulation of the differential equation (3b), which proves that the commodities market is an oscillating system, is just the background for the use of the "goods-moneygoods" process in the oscillation mode. The matter is, that in order to make a particular oscillation process work for the benefit of business, certain conditions are required which would hardly be created on their own.

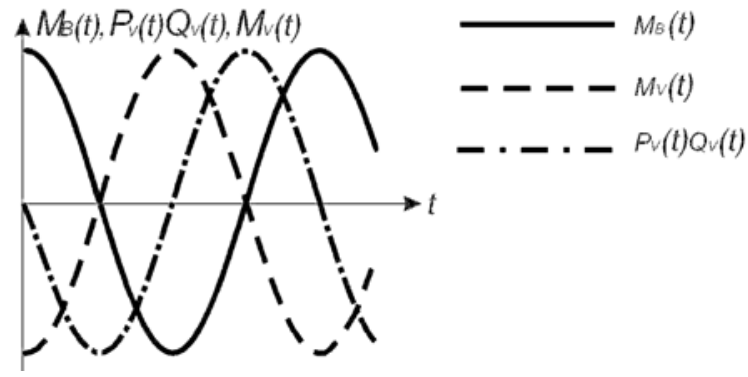

Fig. 2 Chart of processes in the simplest link of the commodities market

In order to have a better understanding, let us give several examples for comparison. If in radioelectronics we take separate details, such as chips, resistors, capacitors, etc., and connect them at random, we would not get either a TV or a computer. If in construction we take separate elements, such as bricks, cement, sanitary ware, fittings, etc., and arrange them at random, we would not get either a residential or a production building. And so on. In order for the above-mentioned complex systems to work, special knowledge is always required.

Economic structures are also complicated systems, even more complicated, as the required objective Crisis-proof economic development - has not yet been attained. Evidently, in order to attain the required objective, we need new knowledge on the formation of economic systems which would meet the required goals, i.e., we need the theory of economic oscillating systems. 
So far we lack this knowledge. The corresponding science has not yet arisen.

Indeed, as shown below, for practical implementation of the "goods-money-goods" oscillation process in the simplest case it is required:

To provide for the linearity of the system, i.e., at least to create the conditions under which $M_{B}, M_{V}, P Q$ could take both positive and negative values in their operation range;

To provide the conditions for changing the values $M_{B}$, $M_{V}, P Q$ in a particular way;

to create the mechanisms for control actions ensuring the necessary changes of $M_{B}, M_{V}, P Q$.

Additional circumstances should obviously be considered for implementation of more complex multi-chain economic systems.

In case these conditions are ignored, the economy, exposed to various chaotic influences, will obviously face processes which are difficult to forecast, similar to the current situation.

The knowledge of the aforementioned circumstances and the mathematical description of the economic "black box" as the system of differential equations already allow developing the abovementioned economic system theory.

Description of this theory goes beyond the scope of the article, therefore, to show the potential of the foregoing approach, we will just give an example of implementation of the oscillation economic process. We will also show that the above mentioned requirements are met. Apparently, other means of implementation can also be suggested, including implementation of the more complicated economic processes.

Example of practical implementation of the "goods-money-goods" oscillation process: Plotted functions of the oscillation process given in Fig. 2 correspond to the initial conditions $M_{B}>0$ (these can be the own capital of the buyer, a bank loan, or invested funds) and $P Q=0$. As is seen, $M_{V}<0$ also meets these initial conditions, which means the ability of the vendor to produce the amount of goods sufficient enough to meet the purchasing power of the buyer, which is why the vendor needs the circulating assets of the buyer.

After the buyer and the vendor reach an agreement on joint business during the first and second quarters of the cycle, the buyer pays the vendor (this is why $P Q<0$ ) the circulating assets, and in the third and fourth quarters of the cycle the vendor supplies the buyer with the goods produced (this is why $P Q>0$ ).
This relation between the flow of circulating assets (in terms of money and in terms of goods) and the polarity of the value of $P Q$ follows from formulae (1) and (2).

Besides, as is seen, in the first quarter of the oscillation process cycle the value $M_{B}$ evidently decreases, as the buyer gradually makes advance payments to the vendor for production of the necessary goods. For the same reason the value $M_{V}$ increases, as in the given isolated functional link of the commodities market the sum of circulating assets of the buyer and the vendor is constant and equals zero.

By the start of the second quarter of the cycle, the buyer has fully exhausted his circulating assets, therefore, $M_{B}=0 ; M_{V}=0$. Thus, further on the vendor continues to produce the required goods paid for by the advance payment of the buyer, to the credit of the buyer. Meanwhile, the value $M_{V}$ grows further and turns positive, whereas the value $M_{B}$ declines further and turns negative.

By the start of the third quarter of the cycle, the value $M_{V}$ reaches its highest, whereas the value $M_{B}$ reaches its lowest. As in the given example we assume the duration of the production process to equal half of the cycle time, in the beginning of the third quarter of the cycle the vendor gradually starts supplying the produced goods to the buyer (for instance, at a wholesale price). Taking into account the market value of the goods supplied to the buyer, the value $M_{B}$ starts increasing, and the value $M_{V}$ decreases.

At the beginning of the fourth quarter of the cycle, the supply of goods paid for by the buyer with his circulating assets runs out, and the vendor starts supplying the goods to the credit of the buyer. This is why, taking into account the market value of goods supplied to the buyer, the value $M_{B}$ growth further, while the value $M_{V}$ continues to decrease.

By the end of the cycle the value $M_{B}$ reaches its highest, and the value $M_{V}$ reaches its lowest. It seems that the oscillation process has returned into its initial state. But this is not quite the case. Indeed, just as at the beginning of the cycle, the vendor has circulating assets $M_{v}<0$. But, besides that, the buyer has to pay back the loan given by the vendor. And the buyer, as opposed to the beginning of the cycle, when he had circulating assets $M_{B}$, at the end of the cycle has goods worth $2 M_{B}$ and owes the vendor the amount of $M_{B}$ for the unpaid loan. This is why, to complete the cycle, the buyer has to pay his debt to 
the vendor. He can either use his own capital, a bank loan, or invested funds.

Thus, the cycle under consideration ends with the buyer purchasing the necessary goods from the vendor. The vendor has certainly included not only the production cost, but also his own profit into the price of the goods.

If the above mentioned process needs to be repeated from time to time, this can be done in the following way:

by the end of the cycle the vendor finds a new buyer and involves him into the next cycle of production and sale of his gods, or if the buyer is a mediator, the latter has to sell the goods purchased in bulk from the vendor in a retail chain and use the circulating assets he obtained to initiate the next cycle of the above described process.

As is seen, the linearity of the aforementioned process is supported by the use of different means of payment for the purchased goods, and the necessary business algorithm is implemented through the respective agreement between the vendor and the buyer. Meanwhile, investment should not be made at a random moment of time, but must correspond to certain phases of the oscillation process.

It is also seen that despite certain "peaks" and "dips" of the respective payments curves (Fig. 2), we cannot see an economic crisis here. Therefore, oscillation processes can indeed be used to manage crisis-proof business processes.

Another well-known example of practical implementation of crisis-free oscillation economic process is agriculture which has a vivid seasonality. At the same time, no one engaged in this business refers to processes observed in winter as crisis, and no one tries to find the ways of fighting them.

An indication of successful business development with the use of oscillation economic processes is certainly the growth of oscillation amplitude. This growth of oscillation amplitude can be achieved both through the well-known means, used, for instance, in extended reproduction, and though the new means, e.g., through the use of resonance economic impact on the oscillation business process.

\section{CONCLUSION}

1. The commodities market, which is the foundation of market economy, is a multilink oscillating system, as the set of "goods-money-goods" processes is described with the system of differential equations of the second order. Due to this, fighting oscillation market processes, implementing the so-called anti- crisis measures is abuse of the nature of the market and cannot be successful.

2. Upturns and downturns of economic development are objective reality and have different economic meaning. The terms "crisis", "stagnation", and the like, reflect the misunderstanding of this circumstance and provoke economic reaction which is inadequate in the current situation.

3. We should not fight economic oscillation processes, but learn to use them. The use of economic oscillation processes allows significantly increasing the efficiency of the controlling economic impact on the market.

4. Knowledge of the above mentioned circumstances and mathematical description of the "black box" of the economy allows developing the theory of economic oscillation systems, which describes, in particular, algorithms for making a crisis-proof economy.

\section{REFERENCES}

Andronov, A.A., Vitt, A.A. \& Khaikin, S.E. (1966). Theory of Oscillators. Oxford: Pergamon Press.

Antonov, A.A. (2010). Differential equation for the "goods-moneygoods" process. European Journal of Scientific Research 40 (1), 27-42.

Balabanian, N. (1994). Electric Circuits. NY: McGraw Hill.

Bannock, G. \& Baxter, R. (2009). The Palgrave Encyclopedia of World Economic History: Since 1750. Basingstoke: Palgrave Macmillan.

Barber, W.J. (2009). A History of Economic Thought. Middletown, CT: Wesleyan University Press.

Bell, D.A. (2009). Fundamentals of Electric Circuits. Oxford University Press.

Bode, H.W. (1945). Network analysis and feedback amplifier design. Princeton, NY: Van Nostrand.

Chebotarev, Yu. (2004). A product of the new economy. Currency speculator, 6, 58 - 61.

Cogdell, J.R. (1999). Foundations of Electric Circuits. NJ: Prentice Hall.

Emelyanov, S.V. (ed). (1995). Variable-Structure Control Systems Discrete and Digital. Malabar, FL: Warrior Books Inc.

Franco, S. (1994). Electric Circuits Fundamentals. Oxford University Press.

Mokyr, J. (ed). (2003). The Oxford Encyclopedia of Economic History. Oxford University Press.

Sabanovic, A., Fridman, L., Spurgeon, S. (eds). (2004). Variable structure systems: from principles to implementation. London: Institution of Electrical Engineers.

Steinmetz, C.P. (2006). Theory and Calculation of Electric Circuits. Wexford College Press.

Zarnowitz, V. (1996). Business Cycles. Theory, History, Indicators, and Forecasting. University of Chicago Press. 